\title{
Adsorption of a Textile Dye from Aqueous Solutions by Carbon Nanotubes
}

\author{
Fernando M. Machado ${ }^{\mathrm{a}, \mathrm{c} *}$, Carlos P. Bergmann ${ }^{\mathrm{a}}$ Eder C. Lima ${ }^{\mathrm{b}}$, \\ Matthew A. Adebayo ${ }^{\text {b Solange B. Fagan }}$
}

\begin{abstract}
${ }^{a}$ Department of Material, Federal University of Rio Grande do Sul - UFRGS, Av. Osvaldo Aranha, 99, Laboratory 705C, CEP 90035-190, Porto Alegre, RS, Brazil

' Institute of Chemistry, Federal University of Rio Grande do Sul-UFRGS, Av. Bento Gonçalves, 9500, CP 15003, CEP 91501-970, Porto Alegre, RS, Brazil

‘Área de Ciências Tecnológicas, Centro Universitário Franciscano-UNIFRA, Rua dos Andradas, 1614, CEP 97010-032, Santa Maria, RS, Brazil
\end{abstract}

Received: June 19, 2013; Revised: November 7, 2013

\begin{abstract}
Multi-walled and single-walled carbon nanotubes were used as adsorbents for the removal of Reactive Blue 4 textile dye from aqueous solutions. The adsorbents were characterised using Raman spectroscopy, $\mathrm{N}_{2}$ adsorption/desorption isotherms and scanning and transmission electron microscopy. The effects of $\mathrm{pH}$, agitation time and temperature on adsorption capacity were studied. In the acidic $\mathrm{pH}$ region, the adsorption of the dye was favourable using both adsorbents. The contact time to obtain equilibrium isotherms at 298-323 K was fixed at 4 hours for both adsorbents. For Reactive Blue 4 dye, Liu isotherm model gave the best fit for the equilibrium data. The maximum sorption capacity for adsorption of the dye occurred at $323 \mathrm{~K}$, attaining values of 502.5 and $567.7 \mathrm{mg} \mathrm{g}^{-1}$ for MWCNT and SWCNT, respectively.
\end{abstract}

Keywords: carbon nanotubes, adsorption, nonlinear isotherm fitting, Reactive Blue 4, isotherm models

\section{Introduction}

Many industries use dyes for colouring their final products. It has been estimated that about 10,000 different synthetic dyes and pigments exist and that over $7 \times 10^{5}$ tonnes are produced annually worldwide ${ }^{1}$. Approximately 10 to $60 \%$ of the reactive dyes are lost during the manufacturing process, producing large quantities of coloured wastewater ${ }^{2}$. The dye-containing wastewater discharged from industry can adversely affect the aquatic environment by impeding light penetration and, as a consequence, precluding photosynthesis of aquatic flora ${ }^{3,4}$. Moreover, most of the dyes can cause allergy, dermatitis, skin irritation and can also induce cancer and cell mutation in humans $\mathrm{s}^{5}$. Therefore, effluents containing dyes require treatment before being released into the environment ${ }^{1-4}$.

The most efficient method for the removal of synthetic dyes from aqueous effluents is the adsorption process ${ }^{6,7}$. This process transfers dyes from the water effluent to a solid phase and remarkably decreases dye bioavailability to living organisms ${ }^{3}$. The decontaminated effluents could be subsequently released to the environment, or the water could be reutilised in industrial processes. The adsorbent can be regenerated or stored in a dry place without direct contact with the environment ${ }^{3}$. Different adsorbents have been used for the removal of dyes from aqueous solutions ${ }^{4,6-8}$. Among these, carbon nanotube (CNTs) materials have been utilised

*e-mail: fernando.machado@ hotmail.com.br for the successful removal of dyes from aqueous effluents ${ }^{7-14}$. CNTs have attracted increasing research interest as a new adsorbent ${ }^{7-14}$. They are attractive alternative adsorbents for the removal of dye contaminants from aqueous effluents because they have large specific surface area, small size as well as hollow and layered structures. CNTs as adsorbents have been found to be efficient with a capacity that exceeds that of activated carbon ${ }^{7-14}$. To the best of our knowledge, there are few papers currently published in the literature reporting the use of CNTs for dye removal from aqueous effluents $^{7-14}$. Therefore, the use of CNTs for dye adsorption requires new studies to be investigated. In the present work, comparative studies and adsorptive capacities of multiwalled carbon nanotubes (MWCNTs) and single-walled carbon nanotubes (SWCNTs) for the effective removal of Reactive Blue 4 (RB-4) textile dye from aqueous solutions were investigated.

\section{Material and Methods}

\subsection{Solutions}

Deionised water was obtained from a Permution Deionizer system (Curitiba, Brazil) and was used for solution preparation throughout the experiments. The textile dye Reactive Blue 4 (RB-4; C.I. 61205; CAS 13324-20-4; $\mathrm{C}_{23} \mathrm{H}_{14} \mathrm{~N}_{6} \mathrm{Cl}_{2} \mathrm{O}_{8} \mathrm{~S}_{2}, 637.429 \mathrm{~g} \mathrm{~mol}^{-1} ; \lambda_{\text {max }}=594 \mathrm{~nm}$; also 
known as Procion Blue MX-R) was supplied by SigmaAldrich (St. Louis, M.O. USA) at $65 \%$ purity. The dye was used without further purification. A stock solution was prepared by dissolving the RB-4 dye in deionised water to a concentration of $5.00 \mathrm{~g} \mathrm{~L}^{-1}$. Working solutions were prepared by diluting the stock solution of the dye to the required concentrations. To adjust the $\mathrm{pH}$ of the solutions, $0.10 \mathrm{~mol} \mathrm{~L}^{-1}$ sodium hydroxide or $0.10 \mathrm{~mol} \mathrm{~L}^{-1}$ hydrochloric acid (Vetec, Rio de Janeiro, Brazil) solution was used. The $\mathrm{pH}$ of the solutions was measured using a Schott Lab 850 set $\mathrm{pH}$ meter (Mainz, Germany).

\subsection{Adsorbents}

SWCNTs were prepared by catalytic chemical vapour deposition (CCVD), using hexane (Merck, Rio de Janeiro, Brazil) as the carbon source and $\mathrm{Fe}-\mathrm{Mo} / \mathrm{MgO}$ as the catalyst precursor $^{15}$. To remove the catalyst, SWCNTs were purified by dispersion in a hydrochloric acid $(37 \% \mathrm{w} / \mathrm{v}$, Vetec, Rio de Janeiro Brazil) solution for $1 \mathrm{~h}$, followed by filtering and washing with deionised water several times, obtaining a purity of higher than $99 \%$. MWCNTs with purity of $95 \%$ were also prepared by CCVD. This synthetic method has been previously described ${ }^{16}$.

The surface analyses and porosity measurements were carried out using a Nova 1000 volumetric adsorption analyser (Quantachrome Instruments, Boynton Beach, USA) at $77 \mathrm{~K}$ (the boiling point of nitrogen). The multipoint BET (Brunauer, Emmett and Teller) and BJH (Barret, Joyner and Halenda) $)^{17,18}$ methods were used for surface area and pore calculations. The morphology of the adsorbents was investigated using scanning electron microscopy (SEM), JEOL microscope, model JSM 6060 (Tokio, Japan) ${ }^{3}$ and transmission electron microscopy (TEM), JEOL microscope, model JEM 2010 (Tokio, Japan $)^{14}$. Raman spectroscopy measurements were done using a 20x objective lens with a $632.8 \mathrm{~nm}$ excitation laser line and a laser power of $\sim 4 \mathrm{~mW}$, via a Jobin Yvon spectrometer, model LabRam (Irvine, USA). The spectra were obtained with a resolution of $1 \mathrm{~cm}^{-1}$ and scans were in the range of $100-4000 \mathrm{~cm}^{-1}$. The point of zero charge $\left(\mathrm{pH}_{\mathrm{pzc}}\right)$ of the adsorbent was determined according to a published procedure ${ }^{19}$.

\subsection{Adsorption studies}

Adsorption studies for the evaluation of the capacity of MWCNT and SWCNT adsorbents for the removal of RB-4 dye from aqueous solutions were carried out in triplicate using a batch contact adsorption method ${ }^{18}$. For these experiments, $30.0 \mathrm{mg}$ of adsorbents were placed in $50 \mathrm{ml}$ flat-bottom Falcon tubes containing $20.0 \mathrm{~mL}$ of the dye solution (100.0 to $\left.1000.0 \mathrm{mg} \mathrm{L}^{-1}\right)$, which were agitated for an appropriate time (0.0833 to $24.00 \mathrm{~h}) \mathrm{using}$ an acclimatized shaker (Oxylab, São Leopoldo, Brazil) at temperatures ranging from 298 to $323 \mathrm{~K}$. The $\mathrm{pH}$ of the dye solutions varied from 2.0 to 10.0 . Subsequently, in order to separate the adsorbents from the aqueous solutions, the flasks were centrifuged at 16,000 rpm for 5 min using a Unicen M Herolab centrifuge (Stuttgart, Germany) and 1-10 mL aliquots of the supernatant were properly diluted with an aqueous solution fixed at a suitable $\mathrm{pH}$ value.

The final concentrations of the dye, which remained in the solution were determined using visible spectrophotometer, T90+ UV-VIS, PG Instruments (London, United Kingdom) provided with quartz optical cells. Absorbance measurements were made at the maximum wavelength of RB-4 dye of $594 \mathrm{~nm}$.

The amount of dye adsorbed and the percentage of dye removal by the adsorbents were calculated using Equations 1 and 2, respectively:

$q=\frac{\left(C_{o}-C_{f}\right)}{m} \cdot V$

$\%$ Removal $=100 \cdot \frac{\left(C_{o}-C_{f}\right)}{C_{o}}$

where $q$ is the amount of dye adsorbed by the adsorbent $\left(\mathrm{mg} \mathrm{g}^{-1}\right), C_{o}$ is the initial dye concentration, which is in contact with the adsorbent $\left(\mathrm{mg} \mathrm{L}^{-1}\right), C_{f}$ is the dye concentration $\left(\mathrm{mg} \mathrm{L}^{-1}\right)$ after the batch adsorption process, $m$ is adsorbent mass $(\mathrm{g})$ and $V$ is the volume of the dye solution (L).

\subsection{Equilibrium models and its statistical evaluation}

The equilibrium of adsorption was evaluated using the Langmuir, Freundlich and Liu isotherm models 9 . The isotherm equations are given in Table 1 .

The fittings of data were done using nonlinear equilibrium models, with successive interactions calculated by the method of Levenberg-Marquardt and interactions calculated by the Simplex method, using the nonlinear fitting facilities of the software Microcal Origin 7.0. In addition, the models were evaluated by the adjusted determination factor $\left(R^{2} a d j\right)$ and an error function $\left(F_{\text {error }}\right)^{14}$, which is a measure of the differences in the theoretical amount of dye taken up by the adsorbent and the $q$ measured experimentally. $R^{2}$ adj and $F_{\text {error }}$ are given in Equations 6 and 7, respectively:

Table 1. Isotherm models.

\begin{tabular}{cc}
\hline Isotherm model & Equation \\
\hline Langmuir & $q_{e}=\frac{Q_{\max } \cdot K_{L} \cdot C_{e}}{1+K_{L} \cdot C_{e}}$ \\
\hline Freundlich & $q_{e}=K_{F} \cdot C_{e}^{1 / n F}$ \\
Liu & $q_{e}=\frac{Q_{\max } \cdot\left(K_{g} \cdot C_{e}\right)^{n L}}{1+\left(K_{g} \cdot C_{e}\right)^{n L}}$
\end{tabular}




$$
R_{a d j}^{2}=\left\{1-\left[1-\left(\frac{\sum_{i}^{n}\left(q_{i, \text { exp }}-\bar{q}_{i, \text { exp }}\right)^{2}-\sum_{i}^{n}\left(q_{i, \text { exp }}-q_{i, \text { odel }}\right)^{2}}{\sum_{i}^{n}\left(q_{i, \text { exp }}-\bar{q}_{i, \text { exp }}\right)^{2}}\right) \cdot\left(\frac{n_{p}-1}{n_{p}-p}\right)\right]\right\}
$$

$$
F_{\text {error }}=\sqrt{\left(\frac{1}{n_{p}-p}\right) \cdot \sum_{i}^{n}\left(q_{i, \exp }-q_{i, \text { model }}\right)^{2}}
$$

where $q_{i, \text { model }}$ is the each q value predicted by the fitting model, $q_{i, \text { exp. }}$ is the each $q$ value measured experimentally, $\bar{q}_{\exp }$ is the average of experimentally measured $\mathrm{q}, n_{p}$ is the number of experiments performed and $p$ is the number of parameters of the fitting model ${ }^{19}$.

\section{Results and Discussion}

\subsection{Characterisation of the adsorbents}

The textural properties of the MWCNTs and SWCNTs adsorbents are presented in Table 2. Taking into account the differences in SWCNTs and MWCNTs, the obtained results reported in Table 2 are in agreement with the expected data $\mathrm{a}^{20}$. Based on these results, it would be expected that SWCNTs would present a higher sorption capacity than MWCNT because the specific surface area and total pore volume of SWCNT were $114.3 \%$ and $91.9 \%$ higher than the respective values of MWCNT. It was also observed that MWCNTs have higher average pore diameter compared to SWCNTs. This higher textural parameter could be attributed to the aggregated pores present in MWCNTs.

TEM and SEM images (Figure 1) show the morphological structure of the MWCNTs (Figures 1a and c) and SWCNTs (Figures $1 \mathrm{~b}$ and d) adsorbents. The SEM image in Figure 1a shows entanglement of MWCNTs and Figure 1b shows SWCNTs in thin bundles. The outer diameters of the MWCNTs (Figure 1c) and SWCNTs (Figure 1d) are in the range of 3-40 $\mathrm{nm}$ and $1-2 \mathrm{~nm}$, respectively. Figure $1 \mathrm{c}$ provides evidence of the "bamboo-like" structure of MWCNTs. Figures 1e and $\mathrm{f}$ show the TEM images of dye adsorbed onto MWCNTs. Clusters of adsorbed RB-4 dye molecules over the MWCNT surface can be seen in the images.

Figures 2a and $\mathrm{b}$ display the Raman spectra of MWCNTs and SWCNTs, respectively. Both spectra were normalised to the G' mode from $2600-2650 \mathrm{~cm}^{-1}$, which does not depend on defect concentration ${ }^{21}$. The Raman spectra of MWCNTs (Figure 2a) differed from the spectra of SWCNTs (Figure $2 \mathrm{~b}$ ) mainly by the absence of the radial breathing modes (RBM) feature. RBM at low frequencies suggests that SWCNTs have a diameter distribution around $1.5 \mathrm{~nm}$ (Figure 2b) ${ }^{21}$. The diamond modes (D) at about $1324 \mathrm{~cm}^{-1}$

Table 2. Textural properties of SWCNT and MWCNT adsorbents.

\begin{tabular}{lccc}
\hline Adsorbents & $\begin{array}{c}\text { Surface Area } \\
\left(\mathbf{m}^{2} / \mathbf{g}\right)\end{array}$ & $\begin{array}{c}\text { Total pore } \\
\text { Volume } \\
\left(\mathbf{c m}^{3} / \mathbf{g}\right)\end{array}$ & $\begin{array}{c}\text { Average pore } \\
\text { diameter } \\
(\mathbf{n m})\end{array}$ \\
\hline SWCNT & 387.66 & 0.662 & 6.83 \\
MWCNT & 180.9 & 0.345 & 7.62 \\
\hline
\end{tabular}

and $1330 \mathrm{~cm}^{-1}$ for SWCNT and MWCNT, respectively, induced by $\mathrm{sp}^{3}$ electronic states (considered to be defects in the planar $\mathrm{sp}^{2}$ graphitic structure $)^{22}$, were visible. The peaks near $1584 \mathrm{~cm}^{-1}$ and $1611 \mathrm{~cm}^{-1}$ for SWCNT and MWCNT, respectively, are the so-called G band, which is related to the graphite $\mathrm{E}_{2 \mathrm{~g}}$ symmetry of the interlayer mode. This mode reflects the structural integrity of $\mathrm{sp}^{2}$-hybridised carbon atoms of the nanotubes. Together, these bands can be used to evaluate the extent of carbon-containing defects ${ }^{22}$. The intensity ratios of the D band to the G band $\left(I_{D} / I_{G}\right)$ of MWCNT and SWCNT were 1.79 and 0.09. The low $I_{D}$ $I_{G}$ ratio of SWCNTs demonstrated the high quality of the samples, practically without defects or amorphous carbon. The MWCNTs exhibited a more disordered structure (Figure 2a), which is supported by the observations from the TEM images (Figure 1c). The more pronounced "bamboolike" structure in the MWCNTs could be considered as reflecting defects in the structure.

\subsection{Effect of contact time on the sorption of $R B-4$}

The influence of contact time in the adsorption of RB-4 using MWCNTs and SWCNTs were carried out using $800.0 \mathrm{mg} \mathrm{L}^{-1}$ of dye solution (Figure 3). It was observed that the minimum contact time between the adsorbate and adsorbents to attain the equilibrium is $3.0 \mathrm{~h}$ for both adsorbents. The contact time was fixed in $4.0 \mathrm{~h}$ for the rest of the experimental work so as to guarantee that this contact time would be sufficient for higher adsorbate concentrations to attain the equilibrium ${ }^{14}$.

\subsection{Effects of $p H$ on adsorption}

One of the most important factors in adsorption studies is the effect of acidity of the medium ${ }^{23}$. Different species may show divergent ranges of suitable $\mathrm{pH}$ depending on the type of adsorbent used. The effects of initial $\mathrm{pH}$ on the percentage of removal of RB-4 dye using MWCNT and SWCNT adsorbents were evaluated within the $\mathrm{pH}$ range of 2 and 10 (Figure 4). For both adsorbents, the percentage of dye removal decreased from $\mathrm{pH} 2.0$ up to 10.0. For the MWCNT and SWCNT adsorbents, the decrease in the percentage of dye removal in the $\mathrm{pH}$ range of 2.0 to 10.0 was $6.81 \%$ and $6.91 \%$, respectively. The values of $\mathrm{pH}_{\mathrm{PZC}}$ for MWCNT and SWCNT adsorbents were 6.85 and 6.73 , respectively. For $\mathrm{pH}$ values lower than $\mathrm{pH}_{\mathrm{pzc}}$, the adsorbent has a positive surface charge. The dissolved RB-4 dye is negatively charged in aqueous solution, because it possesses two sulphonate groups. The adsorption of this dye takes place when the adsorbents has a positive surface charge. For MWCNT and SWCNT, the electrostatic interaction occurs at $\mathrm{pH}<6.85$ and 6.73 , respectively. However, when the $\mathrm{pH}$ value is much lower than $\mathrm{pH}_{\mathrm{pzc}}$, the surface of the adsorbent becomes more positive ${ }^{19}$. This behaviour explains the high adsorption capacity of both adsorbents for RB-4 dye at $\mathrm{pH}$ 2.0. In order to continue the adsorption studies, the initial $\mathrm{pH}$ was fixed at 2.0.

\subsection{Equilibrium studies}

An adsorption isotherm describes the relationship between the amount of adsorbate taken up by the adsorbent $\left(q_{e}\right)$ and the adsorbate concentration remaining in the solution after the system has attained equilibrium $\left(C_{e}\right)$. 


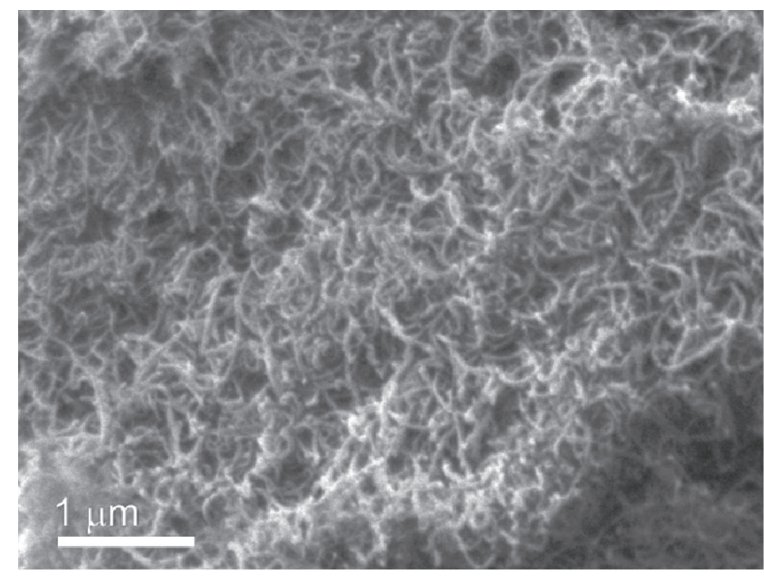

(a)

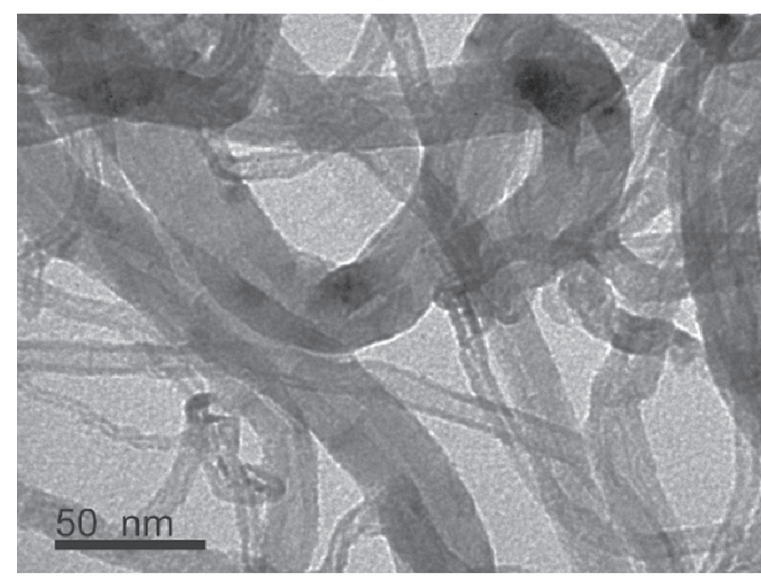

(c)

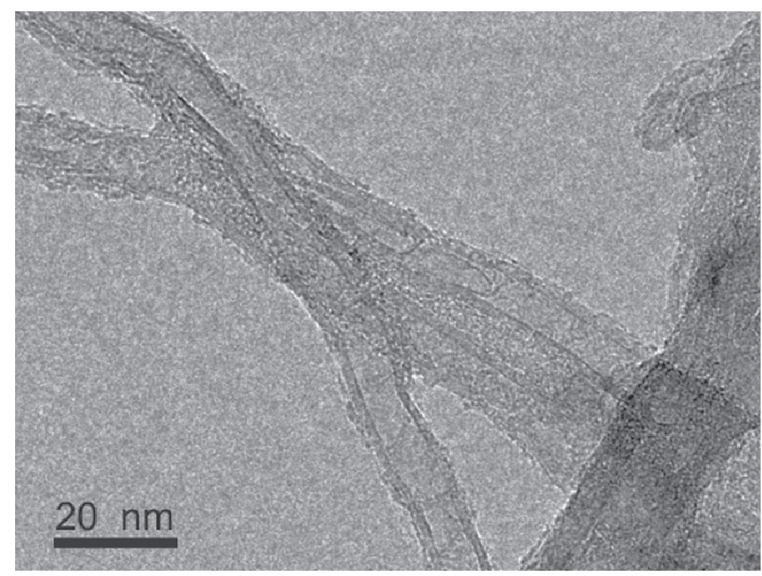

(e)

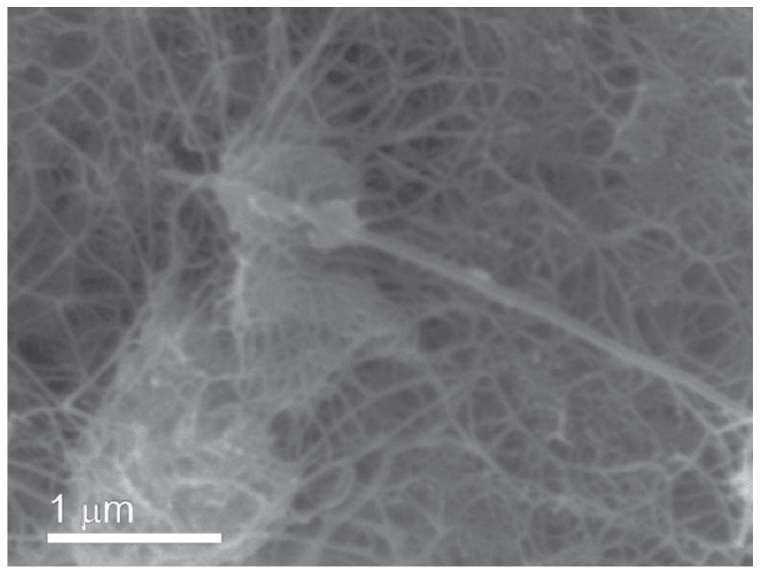

(b)

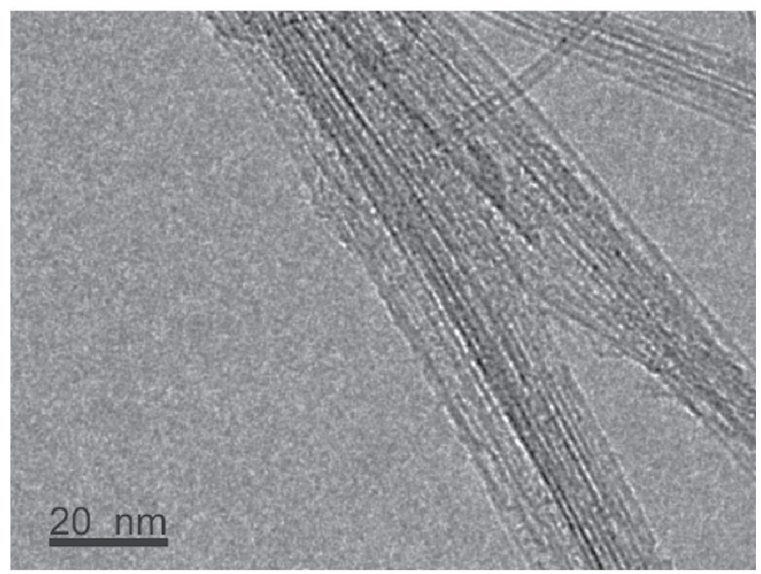

(d)

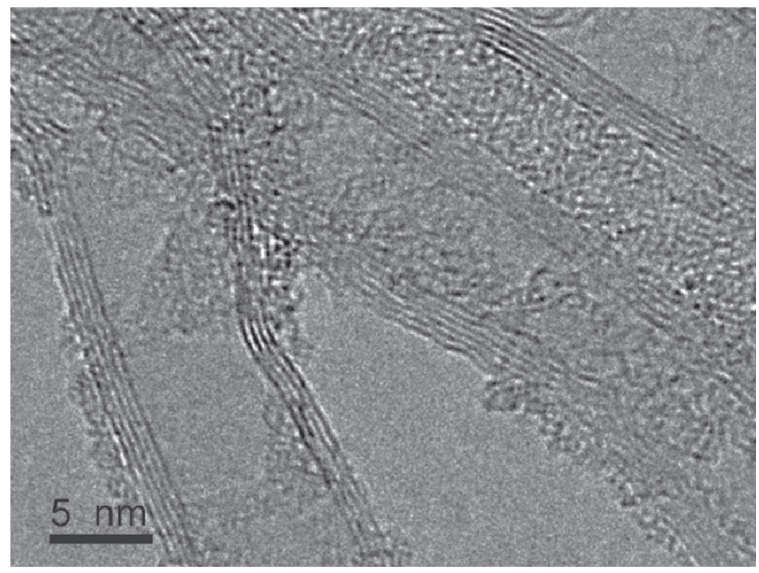

(f)

Figure 1. SEM (a, b) and TEM (c, d, e, f) of nanoadsorbents: (a, c) MWCNT; (b, d) SWCNT and (e, f) RB-4 dye adsorbed MWCNTs.

In this present work, the Langmuir, Freundlich and Liu isotherm models were tested ${ }^{19}$. The Langmuir isotherm model is based on the following principles ${ }^{19}$ : adsorbates are chemically adsorbed at a fixed number of well-defined sites; each site can only take one adsorbate species; all sites are energetically similar; there are no interactions between the adsorbate species. The Freundlich isotherm model assumes that the concentration of the adsorbate on the adsorbent surface increases with the adsorbate concentration. Theoretically, using this expression, an infinite amount of adsorption can occur ${ }^{19}$. The Liu isotherm model ${ }^{19}$ is a combination of the Langmuir and Freundlich isotherm models; therefore, the monolayer assumption of Langmuir model is eliminated and the infinite adsorption assumption that originates from the Freundlich model is also overruled. The Liu model predicts that the active sites of the adsorbent 


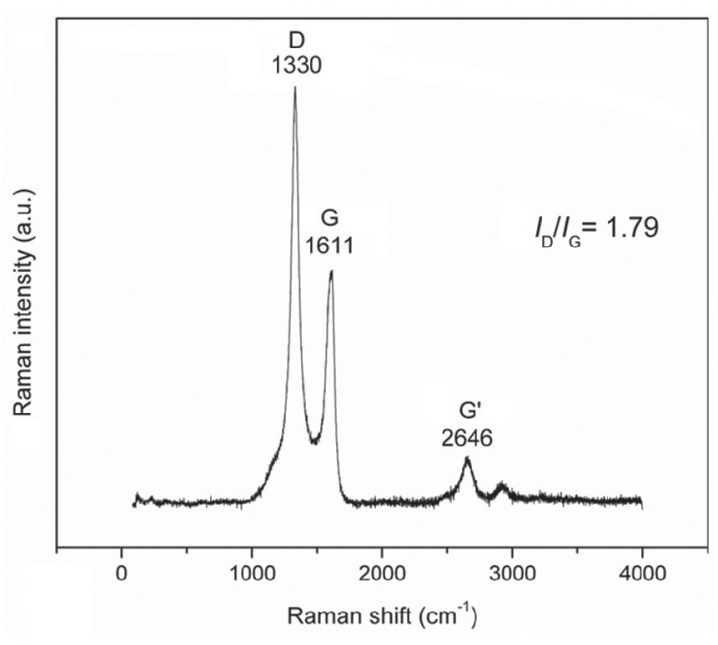

(a)

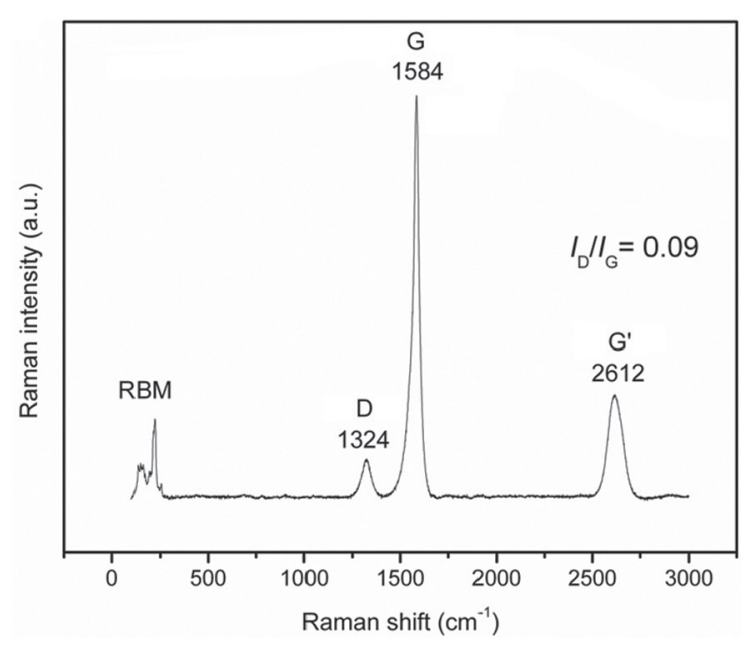

(b)

Figure 2. Raman spectra of adsorbents: (a) MWCNT; (b) SWCNT.

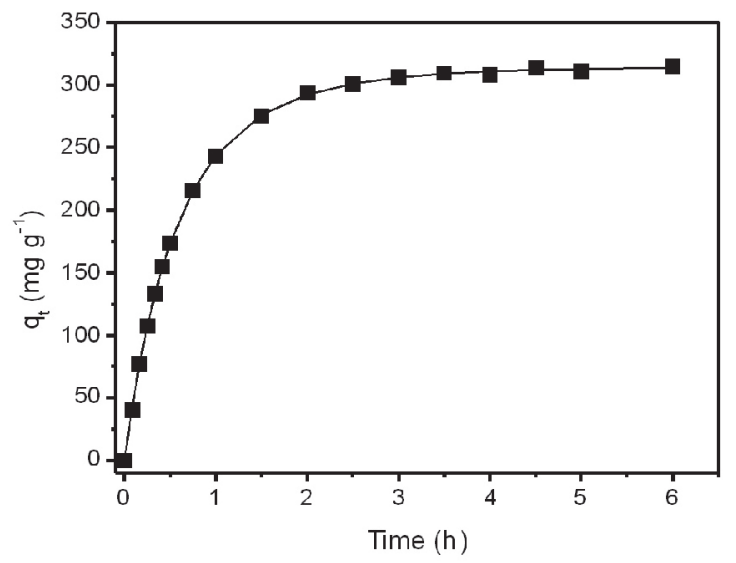

(a)

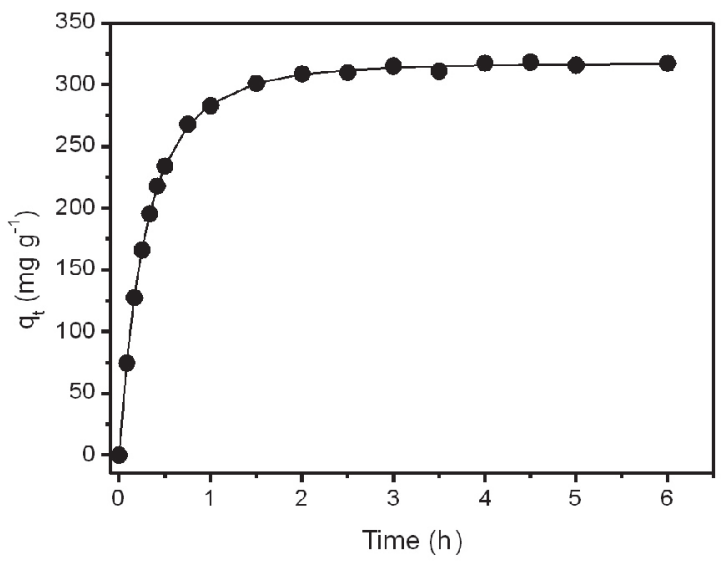

(b)

Figure 3. Effect of contact time on the adsorption of RB-4 dye on MWCNT (a) and SWCNT (b). Conditions: $C_{o} 800.0 \mathrm{mg} \mathrm{L}^{-1}$ of dye solution; mass of adsorbent of $30.0 \mathrm{mg}$; the temperature was fixed at $298 \mathrm{~K}, \mathrm{pH} 2.0$.

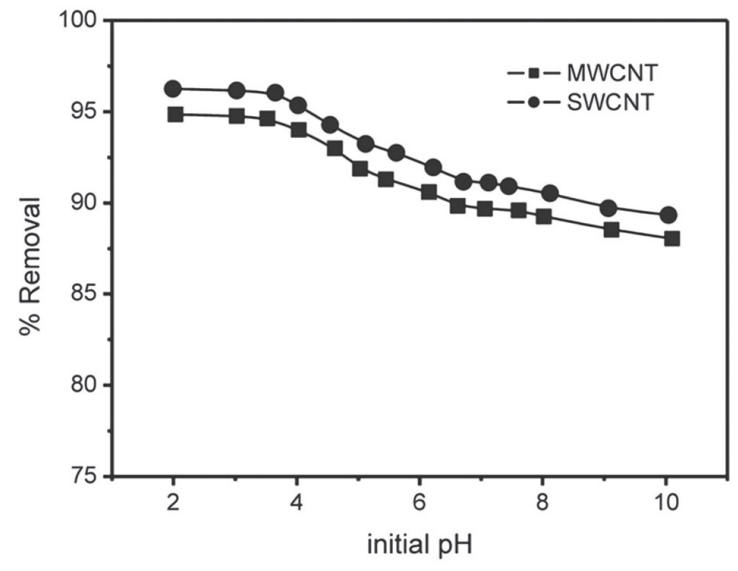

Figure 4. Effect of $\mathrm{pH}$ on the adsorption of RB-4 dye on MWCNT and SWCNT. Conditions: $C_{o} 1000.0 \mathrm{mg} \mathrm{L}^{-1}$ of dye solution; mass of adsorbent of $30.0 \mathrm{mg}$; the temperature was fixed at $298 \mathrm{~K}$. Time of contact between the dye and adsorbate was fixed in $4.0 \mathrm{~h}$. cannot have the same energy. Therefore, the adsorbent may have active sites preferred by the adsorbate molecules for occupation $^{19}$; however, saturation of the active sites should occur unlike in the Freundlich isotherm model. Taking into consideration that the carbon nanotubes have different functional groups as early reported in the literature ${ }^{14}$, it is expected that the active sites of the carbon nanotubes will not have the same energy ${ }^{19}$.

The isotherms of RB-4 adsorption were carried out within the temperature range of 298 to $323 \mathrm{~K}$ on the two adsorbents and were performed using the best experimental conditions previously described (see Figure 5 and Table 3 ). It was observed that the minimum $F_{\text {error }}$ values were obtained by the Liu equilibrium model at all six temperatures studied (Table 3), which means that the theoretical $q$ of isotherm model was close to the experimental $q$. The $F_{\text {error }}$ of each individual model was divided by the $F_{\text {error }}$ of the minimum value $\left(F_{\text {error }}\right.$ ratio) for comparison of different equilibrium models. The Langmuir and Freundlich isotherm models did not suitably fit our experimental data, presenting $F_{\text {error }}$ 


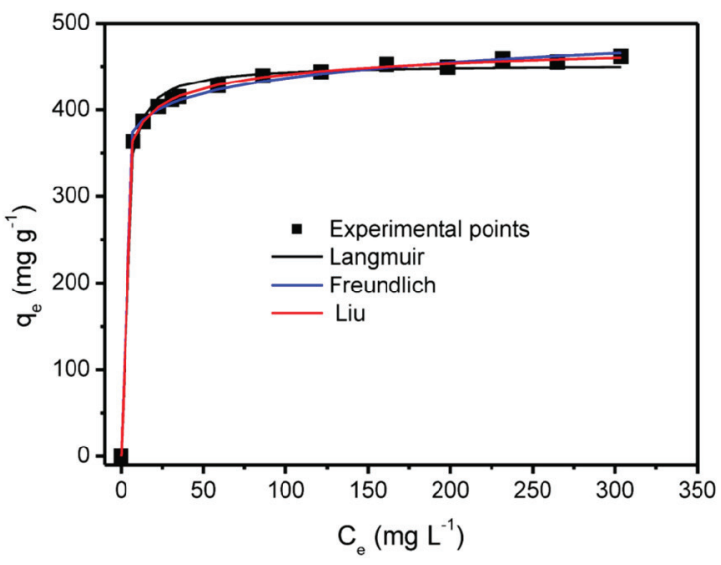

(a)

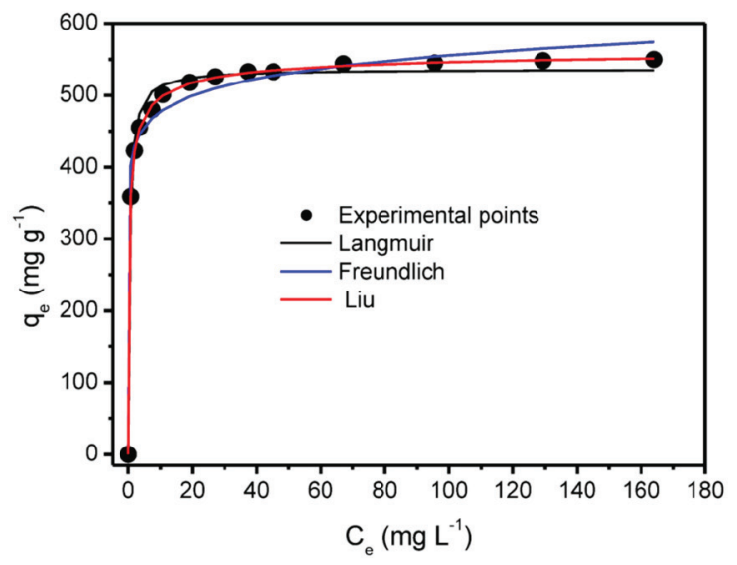

(b)

Figure 5. Isotherm curves of RB-4 adsorption at $323 \mathrm{~K}$ on (a) MWCNT and (b) SWCNT. Conditions: pH was fixed at 2.0; the adsorbent mass was fixed at $30.0 \mathrm{mg}$; the contact time was fixed at $4 \mathrm{~h}$.

Table 3. Liu isotherm parameters for RB-4 adsorption, using MWCNT and SWCNT as adsorbents. Conditions: adsorbent mass of $30.0 \mathrm{mg}$; $\mathrm{pH}$ fixed at 2.0, contact time $4 \mathrm{~h}$.

\begin{tabular}{|c|c|c|c|c|c|c|c|c|c|c|c|c|}
\hline & \multicolumn{6}{|c|}{ MWCNT } & \multicolumn{6}{|c|}{ SWCNT } \\
\hline & $298 \mathrm{~K}$ & $303 \mathrm{~K}$ & $308 \mathrm{~K}$ & $313 \mathrm{~K}$ & $318 \mathrm{~K}$ & $323 \mathrm{~K}$ & $298 \mathrm{~K}$ & $303 \mathrm{~K}$ & $308 \mathrm{~K}$ & $313 \mathrm{~K}$ & $318 \mathrm{~K}$ & $323 \mathrm{~K}$ \\
\hline$Q_{\max }\left(\mathrm{mg} \mathrm{g}^{-1}\right)$ & 442.0 & 457.4 & 467.9 & 478.8 & 488.1 & 502.5 & 487.6 & 518.6 & 532.4 & 544.2 & 552.5 & 567.7 \\
\hline$K_{g}\left(\mathrm{~L} \mathrm{mg}^{-1}\right)$ & 0.5825 & 0.6633 & 0.7707 & 0.9042 & 1.062 & 1.249 & 0.8092 & 0.9490 & 1.115 & 1.341 & 1.681 & 2.008 \\
\hline$n_{L}$ & 0.7021 & 0.5182 & 0.4901 & 0.4827 & 0.4032 & 0.3789 & 0.4343 & 0.2965 & 0.7203 & 0.6196 & 0.5649 & 0.5480 \\
\hline$R^{2}$ & 0.9998 & 0.9999 & 0.9996 & 0.9997 & 0.9997 & 0.9997 & 0.9997 & 0.9999 & 0.9994 & 0.9997 & 0.9998 & 0.9997 \\
\hline$F_{\text {error }}$ & 1.802 & 1.421 & 2.260 & 2.112 & 2.218 & 2.111 & 1.985 & 1.495 & 3.614 & 2.199 & 2.105 & 2.480 \\
\hline
\end{tabular}

ratio values ranging from 3.75 to 17.8 (MWCNT) and from 2.54 to 27.2 (SWCNT). Similarly, the Freundlich isotherm presented $F_{\text {error }}$ ratio ranging from 2.52 to 19.4 (MWCNT) and from 7.03 to 14.1 (SWCNT). For this reason, the isotherm parameters of the Langmuir and Freundlich models were not presented in Table 3 because these values have no physical meaning. The maximum amounts of RB-4 uptake were 502.5 and $567.7 \mathrm{mg} \mathrm{g}^{-1}$ for MWCNT and SWCNT, respectively. These values indicate that these adsorbents are very good adsorbents for RB-4 dye removal from aqueous solutions. It should be emphasised that the maximum amount of RB-4 dye adsorbed on SWCNT was $13.0 \%$ higher than the corresponding value obtained for MWCNT. The textural characteristics of MWCNT discussed in section 3.1 explain this difference.

\subsection{Thermodynamic studies}

Thermodynamic parameters of the adsorption process; Gibb's free energy change $\left(\Delta G^{\circ}, \mathrm{kJ} \mathrm{mol}^{-1}\right)$, enthalpy change $\left(\Delta H^{\circ}, \mathrm{kJ} \mathrm{mol}^{-1}\right)$ and entropy change $\left(\Delta S^{\circ}, \mathrm{J} \mathrm{mol}^{-1} \mathrm{~K}^{-1}\right)$ were determined using Equations 8, 9 and 10.

$\Delta \mathrm{G}^{\mathrm{o}}=\Delta \mathrm{H}^{\mathrm{o}}-\mathrm{T} \Delta \mathrm{S}^{\mathrm{o}}$

$\Delta \mathrm{G}^{\mathrm{o}}=-\mathrm{RTLn}(\mathrm{K})$

The combination of Equations 8 and 9 gives Equation 10:

$\operatorname{Ln}(K)=\frac{\Delta S^{\mathrm{o}}}{R}-\frac{\Delta H^{\mathrm{o}}}{R} \times \frac{1}{T}$ where $R$ is the universal gas constant $\left(8.314 \mathrm{~J} \mathrm{~K}^{-1} \mathrm{~mol}^{-1}\right)$, $T$ is the absolute temperature (Kelvin) and $K$ represents the equilibrium adsorption constants of the isotherm fits. It has been observed different isotherm models gave different adsorption equilibrium constants $(K)^{[14,19,23-27]}$. Thermodynamic parameters of adsorption can be evaluated from the $K_{0}$ (Liu equilibrium constant), as already reported ${ }^{14,19,27^{\circ}}$.

The $\Delta H^{\circ}$ and $\Delta S^{\circ}$ values can be calculated from the slope and intercept of the linear plot of $\operatorname{Ln}(K)$ versus $1 / T$.

The thermodynamic data are presented in Table 4 . The $R^{2}$ values of the linear fit were $\approx 0.99$, indicating that the values of enthalpy and entropy calculated for both adsorbents are reliable. In addition, the magnitude of enthalpy was in agreement with the electrostatic interaction of an adsorbent with an adsorbate ${ }^{28}$. This kind of interaction can be classified, to a certain extent, by the magnitude of enthalpy change. Physisorption processes, such as van der Waals interactions, are usually lower than $20 \mathrm{~kJ} \mathrm{~mol}^{-1}$. Electrostatic interactions varies from 20 to $80 \mathrm{~kJ} \mathrm{~mol}^{-1}$; this kind of interaction is classified as physisorption ${ }^{28}$. Chemisorption bond strengths can be in the range of $80-450 \mathrm{~kJ} \mathrm{~mol}^{-1[28]}$. Enthalpy changes $\left(\Delta H^{\circ}\right)$ indicate that the adsorption is an endothermic processes. Negative values of $\Delta G$ imply that the RB-4 reactive dye adsorption by MWCNT and SWCNT adsorbents was a spontaneous process and a favourable process at all the experimental temperatures. The positive values of $\Delta S^{\circ}$ is a confirmation of high preference of RB-4 molecules on the surface of MWCNT and SWCNT, and suggested the possibility of 
Table 4. Thermodynamic parameters of the adsorption of RB-4 dye on MWCNT and SWCNT adsorbents. Conditions: adsorbent mass $30.0 \mathrm{mg}, \mathrm{pH}$ fixed at 2.0 ; contact time of $4 \mathrm{~h}$.

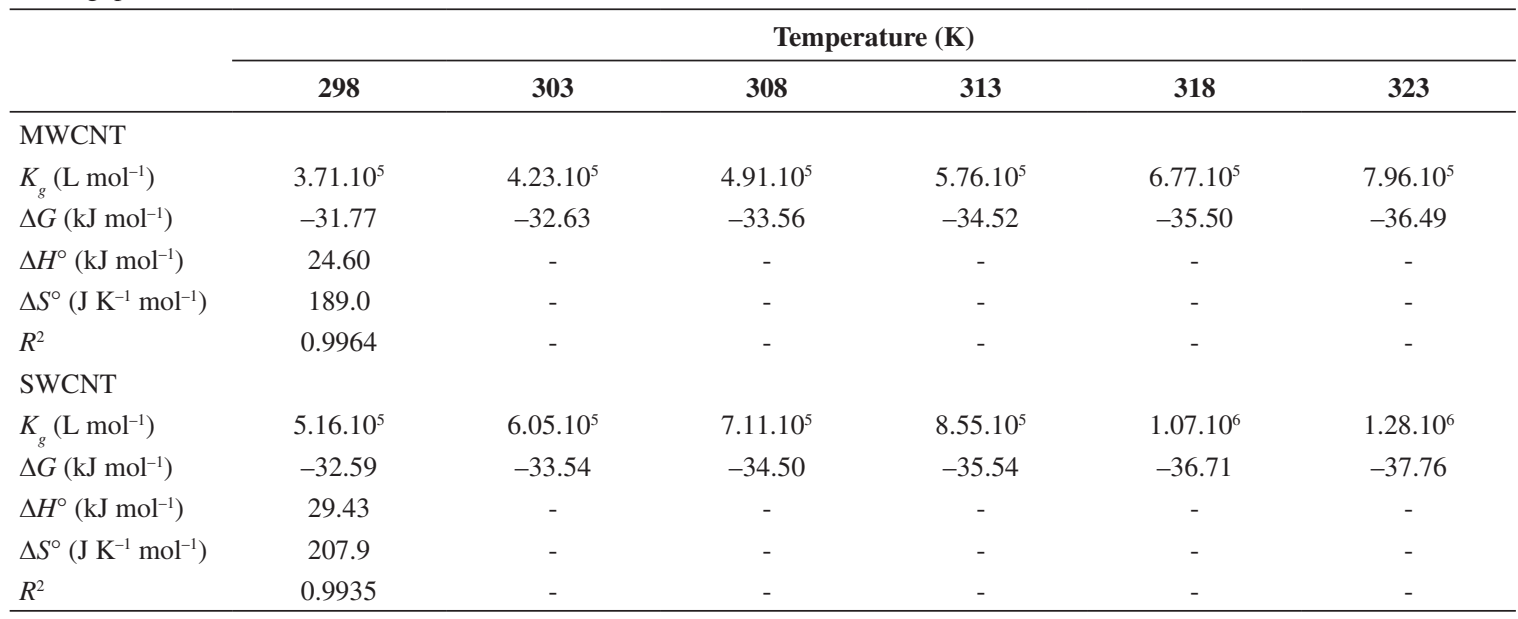

some structural changes or readjustments in the dye-carbon adsorption complex ${ }^{29}$. In addition, the dehydration of a dye molecule took place before its adsorption to a carbon surface, and the release of these water molecules to the bulk solution. The increment in the adsorption capacities of MWCNT and SWCNT at higher temperatures could be attributed to the enhanced mobility and penetration of dye molecules within the adsorbent porous structures by overcoming the activation energy barrier and enhancing the rate of intra-particle diffusion ${ }^{29}$.

\section{Conclusions}

Multi-walled carbon nanotubes (MWCNTs) and single-walled carbon nanotubes (SWCNTs) were good adsorbents for removing Reactive Blue 4 (RB-4) textile dye from aqueous solutions. The RB-4 dye interacted

\section{References}

1. Koprivanac N and Kusic H. Hazardous organic pollutants in colored wastewaters. New York: New Science Publishers; 2008.

2. Hessel C, Allegre C, Maisseu M, Charbit F and Moulin P. Guidelines and legislation for dye house effluents. Journal of Environmental Management. 2007; 83:171180. PMid:16701938. http://dx.doi.org/10.1016/j. jenvman.2006.02.012

3. Cardoso NF, Lima EC, Pinto IS, Amavisca CV, Royer B, Pinto RB et al. Application of cupuassu shell as biosorbent for the removal of textile dyes from aqueous solution. Journal of Environmental Management. 2011; 92:12371247. PMid:21195535. http://dx.doi.org/10.1016/j. jenvman.2010.12.010

4. Royer B, Cardoso NF, Lima EC, Macedo TR and Airoldi C. A useful organofunctionalized layered silicate for textile dye removal. Journal of Hazardous Materials. 2010; 181:366374. PMid:20554108. http://dx.doi.org/10.1016/j. jhazmat.2010.05.019

5. Carneiro PA, Umbuzeiro GA, Oliveira DP and Zanoni MVB. Assessment of water contamination caused by a mutagenic textile effluent/dyehouse effluent bearing disperse dyes. Journal of Hazardous Materials. 2010; 174:694-699. PMid:19853375. http://dx.doi.org/10.1016/j.jhazmat.2009.09.106 with the MWCNT and SWCNT adsorbents at the solid/ liquid interface when suspended in water. The equilibrium isotherm of the RB-4 dye was obtained, and Liu isotherm model gave the best fit. The maximum adsorption capacities were 502.5 and $567.7 \mathrm{mg} \mathrm{g}^{-1}$ for MWCNT and SWCNT, respectively. The enthalpy $\left(\Delta H^{\circ}\right)$ of adsorption signified that adsorption was an endothermic process and the magnitude of enthalpy was consistent with an electrostatic interaction of an adsorbent with the dye.

\section{Acknowledgements}

The authors are grateful to Conselho Nacional de Desenvolvimento Científico e Tecnológico $(\mathrm{CNPq})$ and to The Academy of Sciences for Developing World (TWAS, Italy) for financial support and fellowships.

6. Royer B, Cardoso NF, Lima EC, Ruiz VSO, Macedo TR and Airoldi C. Organofunctionalized kenyaite for dye removal from aqueous solution. Journal of Colloid and Interface Science. 2009; 336:398-405. PMid:19447406. http://dx.doi. org/10.1016/j.jcis.2009.04.025

7. Gupta VK, Kumar R, Nayak A, Saleh TA and Barakat MA, Adsorptive removal of dyes from aqueous solution onto carbon nanotubes: A review. Advances in Colloid and Interface Science. 2013; 193:24-34. PMid:23579224. http://dx.doi. org/10.1016/j.cis.2013.03.003

8. Gao HJ, Zhao SY, Cheng XY, Wang XD and Zheng LQ. Removal of anionic azo dyes from aqueous solution using magnetic polymer multi-wall carbon nanotube nanocomposite as adsorbent. Chemical Engineering Journal. 2013; 223:84-90. http://dx.doi.org/10.1016/j.cej.2013.03.004

9. Geyikci F. Adsorption of Acid Blue 161 (AB 161) Dye from Water by Multi-walled Carbon Nanotubes. Fullerenes Nanotubes and Carbon Nanostructures. 2013; 21:579-593. http://dx.doi.org/10.1080/1536383X.2011.643428

10. Ghaedi M and Kokhdan SN. Oxidized multiwalled carbon nanotubes for the removal of methyl red (MR): kinetics and equilibrium study. Desalination and Water Treatment. 2012, 49:317-325. http://dx.doi.org/10.1080/194 43994.2012.719355 
11. Ghaedi M, Khajehsharifi H, Yadkuri AH, Roosta M and Asghari A. Oxidized multiwalled carbon nanotubes as efficient adsorbent for bromothymol blue. Toxicological and Environmental Chemistry. 2012; 94:873-883. http://dx.doi.or $\mathrm{g} / 10.1080 / 02772248.2012 .678999$

12. Kuo CY, Wu CH and Wu JY. Adsorption of direct dyes from aqueous solutions by carbon nanotubes: Determination of equilibrium, kinetics and thermodynamics parameters. Journal of Colloid and Interface Science. 2008; 327:308-315. PMid:18786679. http://dx.doi.org/10.1016/j.jcis.2008.08.038

13. Qu S, Huang F, Yu S, Chen G and Kong J. Magnetic removal of dyes from aqueous solution using multi-walled carbon nanotubes filled with $\mathrm{Fe}_{2} \mathrm{O}_{3}$ particles. Journal of Hazardous Materials. 2008; 160:643-647. PMid:18430510. http://dx.doi. org/10.1016/j.jhazmat.2008.03.037

14. Machado FM, Bergmann CP, Fernandes THM, Lima EC, Royer B, Calvete T et al. Adsorption of Reactive Red $\mathrm{M}-2 \mathrm{BE}$ dye from water solutions by multi-walled carbon nanotubes and activated carbon. Journal of Hazardous Materials. 2011; 192:1122-1131. PMid:21724329. http:// dx.doi.org/10.1016/j.jhazmat.2011.06.020

15. Lima MD, De Andrade MJ, Locatteli A, Balzaretti N, Nobre $\mathrm{F}$, Bergmann CP et al. The effect of the combustible agents on the synthesis of $\mathrm{Fe}-\mathrm{Mo} / \mathrm{MgO}$ catalysts for the production of carbon nanotubes. Physica Status Solidi (B). 2007; 244:39013906. http://dx.doi.org/10.1002/pssb.200776115

16. Bierdel M, Buchholz S, Michele V, Mleczko L, Rudolf R, Voetz $\mathrm{M}$, et al. Industrial production of multiwalled carbon nanotubes. Physica Status Solidi (B). 2007; 244:3939-3943. http://dx.doi. org/10.1002/pssb.200776101

17. Vaghetti JCP, Zat M, Bentes KRS, Ferreira LS, Benvenutti EV and Lima EC. 4-Phenylenediaminepropylsilica xerogel as a sorbent for copper determination in waters by slurry-sampling ETAAS. Journal of Analytical Atomic Spectrometry. 2003; 18:376-380. http://dx.doi.org/10.1039/ b209133j

18. Jacques RC, Lima EC, Dias SLP, Mazzocato AC and Pavan FA. Yellow Passion-Fruit Shell as Biosorbent to Remove Cr(III) and $\mathrm{Pb}(\mathrm{II})$ from Aqueous Solution. Separation Science and Technology. 57:193-198.

19. Prola LDT, Acayanka E, Lima EC, Umpierres CS, Vaghetti JCP, Santos WO et al. Comparison of Jatropha curcas shells in natural form and treated by non-thermal plasma as biosorbents for removal of Reactive Red 120 textile dye from aqueous solution. Industrial Crops and Products. 2013; 46:328-340. http://dx.doi.org/10.1016/j.indcrop.2013.02.018

20. Serp P, Corrias M and Kalck P. Carbon nanotubes and nanofibers in catalysis. Applied Catalysis A: General. 2003; 25:337-358. http://dx.doi.org/10.1016/S0926-860X(03)00549-0

Apendix 1. Nomenclature.

$C_{e} \quad$ dye concentration at the equilibrium $\left(\mathrm{mg} \mathrm{L}^{-1}\right)$.

$C_{f} \quad$ dye concentration at ending of the adsorption $\left(\mathrm{mg} \mathrm{L}^{-1}\right)$.

$C_{o} \quad$ initial dye concentration put in contact with the adsorbent (mg L-1).

$K$ equilibrium adsorption constants of the isotherm fits.

$K_{F} \quad$ the Freundlich equilibrium constant $\left[\mathrm{mg} \mathrm{g}^{-1}\left(\mathrm{mg} \mathrm{L}^{-1}\right)^{-1 / n F}\right]$.

$K_{L} \quad$ the Langmuir equilibrium constant $\left(\mathrm{L} \mathrm{mg}^{-1}\right)$.

$K_{g} \quad$ the Liu equilibrium constant $\left(\mathrm{L} \mathrm{mg}^{-1}\right)$.

$m \quad$ the adsorbent mass $(\mathrm{g})$.

$n_{p} \quad$ number of experiments performed.

$n_{F} \quad$ dimensionless exponent of the Freundlich equation.
21. Jorio A, Pimenta MA, Souza AG, Saito R, Dresselhaus $\mathrm{G}$ and Dresselhaus MS. Characterizing carbon nanotube samples with resonance Raman scattering. New Journal of Physics. 2003; 5:139(1)-139(17).

22. Dresselhaus MS, Dresselhaus G, Jorio A, Souza AG $F^{\circ}$ and Saito R. Raman spectroscopy on isolated single wall carbon nanotubes. Carbon. 2002; 40:2043-2061. http://dx.doi. org/10.1016/S0008-6223(02)00066-0

23. Alencar WS, Lima EC, Royer B, dos Santos BD, Calvete T, Da Silva EA et al. Application of aqai stalks as biosorbents for the removal of the dye Procion Blue MX-R from aqueous solution. Separation Science and Technology. 2012; 47:513-526. http:// dx.doi.org/10.1080/01496395.2011.616568

24. Alencar WS, Acayanka E, Lima EC, Royer B, De Souza FE, Lameira J et al Application of Mangifera indica (mango) seeds as a biosorbent for removal of Victazol Orange 3R dye from aqueous solution and study of the biosorption mechanism. Chemical Engineering Journal. 2012; 209:577-588. http:// dx.doi.org/10.1016/j.cej.2012.08.053

25. Gupta VK, Gupta B, Rastogi A, Agarwal S and Nayak A. A comparative investigation on adsorption performances of mesoporous activated carbon prepared from waste rubber tire and activated carbon for a hazardous azo dye-Acid Blue 113. Journal of Hazardous Materials. 2011; 186:891901. PMid:21163571. http://dx.doi.org/10.1016/j. jhazmat.2010.11.091

26. Nethaji S, Sivasamy A. Adsorptive removal of an acid dye by lignocellulosic waste biomass activated carbon: Equilibrium and kinetic studies. Chemosphere. 2011; 82:13671372. PMid:21176940. http://dx.doi.org/10.1016/j. chemosphere.2010.11.080

27. Cardoso NF, Lima EC, Royer B, Bach MV, Dotto GL, Pinto LAA et al. Comparison of Spirulina platensis microalgae and commercial activated carbon as adsorbents for the removal of Reactive Red 120 dye from aqueous effluents. Journal of Hazardous Materials. 2012; 241242:146-153. PMid:23040660. http://dx.doi.org/10.1016/j. jhazmat.2012.09.026

28. Sun CL and Wang CS. Estimation on the intramolecular hydrogen-bonding energies in proteins and peptides by the analytic potential energy function. Journal Of Molecular Structure. 2010; 956:38-43. http://dx.doi.org/10.1016/j. theochem.2010.06.020

29. Asouhidou DD, Triantafyllidis KS, Lazaridis NK, Matis KA, Kim SS and Pinnavaia TJ. Sorption of reactive dyes from aqueous solutions by ordered hexagonal and disordered mesoporous carbons. Microporous and Mesoporous Materials. 2009;117:257-67. http://dx.doi.org/10.1016/j. micromeso.2008.06.034

\footnotetext{
$n_{L} \quad$ dimensionless exponent of the Liu equation.

$p \quad$ number of parameters of the fitted model.

$q \quad$ amount adsorbed of the dye by the adsorbent $\left(\mathrm{mg} \mathrm{g}^{-1}\right)$.

$q_{e} \quad$ amount adsorbate adsorbed at the equilibrium $\left(\mathrm{mg} \mathrm{g}^{-1}\right)$.

$q_{i, \text { model }}$ each value of $q$ predicted by the fitted model.

$q_{i, \text { exp. }} \quad$ each value of $q$ measured experimentally.

$\bar{q}_{\text {exp }} \quad$ average of $q$ measured experimentally.

$Q_{\max }$ the maximum adsorption capacity of the adsorbent $\left(\mathrm{mg} \mathrm{g}^{-1}\right)$.

$R^{2} \quad$ adjusted determination factor.

$V \quad$ volume of the dye solution (L).
} 